\section{Internships initiative of the ISCB- Student Council}
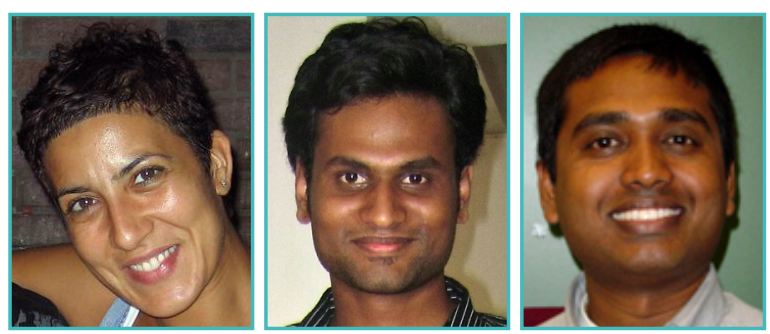

Noura Chelbat', Avinash Kumar Shanmugam², Venkata P. Satagopam ${ }^{3}$

'Institute of Bioinformatics, JKU,Linz Austria, ${ }^{2}$ Center for Computational Medicine and Biology, UM, Ann Arbor, Michigan, ${ }^{3}$ Structural and Computational Biology, EMBL, Heidelberg,Germany

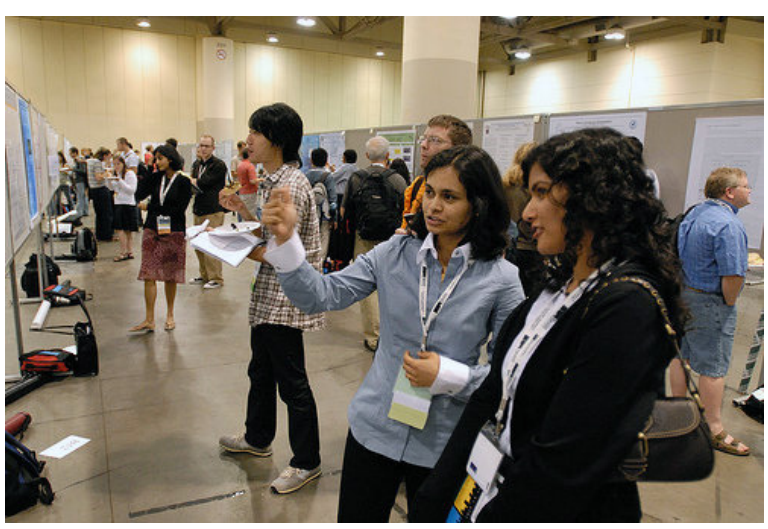

Participants in the poster session at the Student Council Symposium, Toronto, 2008

The ISCB Student Council' (ISCB-SC) represents students and young professionals involved in bioinformatics and related fields all over the world as the student organization of the International Society for Computational Biology 2 .

The idea is promote young researchers in the field through different initiatives. One such initiative of the ISCB-SC is the developing nation's internships program initiated one year ago. The main aim is to provide a fellowship for students to spend from 3 up to 6 months. Through this initiative we try to find funded internship positions in labs for students from developing countries so as to give them a chance to work with experienced researchers and gain valuable knowledge and

1 http://www.iscbsc.org/

2 http://www.iscb.org/

\section{isab Student 200 COUNCIL}

INTERNATIONAL SOCIETY FOR COMPUTATIONAL BIOLOGY

skills. They can then spread these among students and researchers in their home country.

How does it work?

- If a PI has an open position in his/her lab that they would like to offer to a student from a developing country, they can inform us about the position along with their criteria for students to fill that position (skills required, previous experience, stipend amount, duration etc).

- The Student Council will then call for applications from students and screen through these applications as per the given criteria and shortlist the most promising applications.

- These applications will then be forwarded to the PI who can select a student from these to fill the position.

Please note that the screening and short listing will be based on the criteria set by the PI. The PI is free to be involved as much or as little in the process as they wish to be.

Since the beginning of this initiative, about one year ago, we were offered various positions; one of them at at the lab of Dr. Reinhard Schneider at EMBL, Heidelberg, which was successfully filled by a student from Estonia. We are currently accepting applications for one more position at the lab of Dr. Burkhard Rost at TU Munich. (Details can be found at http://iscbsc.org/content/careercentral).

We are hoping that more Pls will be willing to offer positions at their labs so that many more students from developing countries can benefit from this!

If you are interested, please get in touch with us at internships@iscbsc.org. We hope to hear from you!

\section{Regards,}

The ISCB-SC internship team

"Far and away, the best prize life has to offer is the chance to work hard at work worth doing"

- Theodore Roosevelt 